\title{
Adaptive Controllers for Enhancement of Stand-Alone Hybrid System Performance
}

\author{
Yew Weng Kean, Agileswari Ramasamy, Shivashankar Sukumar, Marayati Marsadek \\ Institute of Power Engineering (IPE), Universiti Tenaga Nasional, Selangor, Malaysia
}

\begin{tabular}{l}
\hline \hline Article Info \\
\hline Article history: \\
Received May 17, 2018 \\
Revised Jul 22, 2018 \\
Accepted Aug 9, 2018 \\
\hline
\end{tabular}

\section{Keyword:}

Adaptive controller

Optimization

PI controller

Stand-alone hybrid system

Renewable energy

\begin{abstract}
This paper presents a stand-alone hybrid renewable energy system (SHRES) consisting of solar photovoltaic (PV), wind turbine (WT) and battery energy storage (BES) in an effort reduce the dependence on fossil fuels. The renewable energy sources have individual inverters and the PV inverter of the SHRES is operated using active and reactive power control. The PV inverter have two main control structures which are active power control and reactive power control and each contain a proportional integral (PI) controller. Accurate control of the PV inverter's active power is essential for PV curtailment applications. Thus, this paper aims to enhance the performance of the SHRES in this work by optimizing the performance of the PV inverter's active power PI controller parameters through the design of adaptive controllers. Therefore, an adaptive controller and an optimized adaptive controller are proposed in this paper. The performances of the proposed controllers are evaluated by minimizing the objective function which is the integral of the time weighted absolute error (ITAE) criterion and this performance is then compared with a controller that is tuned by the traditional trial and error method. Simulation results showed that the optimized adaptive controller is better as it recorded an error improvement of $42.59 \%$. The dynamic optimized adaptive controller is more adept at handling the fast changes of the SHRES operation.
\end{abstract}

Copyright (C) 2018 Institute of Advanced Engineering and Science. All rights reserved.

\section{Corresponding Author:}

Yew Weng Kean,

Institute of Power Engineering (IPE), Universiti Tenaga Nasional,

Jalan Ikram-Uniten, 43000 Kajang, Selangor, Malaysia.

Email: wkyew90@hotmail.com

\section{INTRODUCTION}

The world is shifting its focus from fossil fuels to renewable energy sources (RES) to cope with the ever increasing energy demand. However, the output power from RES such as solar photovoltaic (PV) and wind turbine (WT) is intermittent in nature. In order to overcome this problem, hybrid system consisting of RES is operated with energy storage system. The stand-alone hybrid renewable energy system (SHRES) in this work consists of solar photovoltaic (PV), wind turbine (WT) and battery energy storage (BES) that will be supplying power to AC loads. The distributed generated (DG) sources in the SHRES have individual inverters which have complex controls involving proportional integral (PI) controllers [1].

PI controller have been used for many decades, and its parameters are commonly found using the traditional method such as Zigler and Nichols method and trial and error method [2]. These PI controllers have simple control structures but they are unable to withstand nonlinear and complex systems of the SHRES without precise tuning [3]. Authors in [4] utilized the linear programming method for the tuning of PID controller parameters. The authors in [5] highlighted that there is a need to optimize the PI controller's parameters in order to overcome the tedious and time-consuming tuning process through the traditional methods. Therefore the authors applied the artificial bee colony (ABC) method on the PI controllers of a PV and fuel cell (FC) hybrid system and it provided positive results in both overshoot percentage and steady 
state error. Similarly, it was documented in [6] that the control parameters obtained using the genetic algorithm (GA) is better than the traditional method in terms of peak deviation and settling time. Although the linear programming, $\mathrm{ABC}$ and GA optimization techniques are able to provide better results than the traditional method, they require significantly high computational time [7]. The fixed gains from these optimization techniques are also unable to handle fast changes of operation points in a complex system. Alternatively, the authors in [8] designed an adaptive controller to stabilize the microgrid's islanded operation. However, the authors considered an adaptive controller only for the voltage and reactive power control PI controller. From the literature, it was observed that various ways was used to optimize the PI controllers to improve its performance. However, limited literature is available on the design of adaptive controller that focuses solely on optimizing the inverter's active power control PI controller.

In this work, the PV and WT inverter of the SHRES is operated using active and reactive power control while the BES is operated using voltage and frequency control. The PV inverter have two main control structures which are active power control and reactive power control and each contain a proportional integral (PI) controller with two key parameters namely; proportional gain $(\mathrm{Kp})$ and integral time constant (Ti). Accurate control of the PV inverter's active power is essential for PV curtailment applications. Thus, this paper aims to optimize the active power PI controller parameters of the PV inverter through the design of adaptive controllers to improve the performance of the SHRES. As a result, an adaptive controller and optimized adaptive controller are proposed. The performances of the proposed adaptive controllers are evaluated by minimizing the integral of the time weighted absolute error (ITAE) criterion. The results of the proposed adaptive controllers are then compared with the result of the controller using the traditional trial and error method. The paper is organized as follows: Section 2 discusses the overview of the SHRES model and its control strategy while the proposed methodology for the implementation of the adaptive controllers is discussed in Section 3. Section 4 presents and discusses the simulation results of the adaptive controllers using the PSCAD software. Lastly, a conclusion is drawn in Section 5.

\section{OVERVIEW OF THE SHRES MODEL}

The SHRES in this work consist of three DG sources namely PV, WT and battery energy storage (BES) and is designated for 10 houses in a rural area in Malaysia. The PV, WT and BES are rated 7.5kW, $3 \mathrm{~kW}$ and $81 \mathrm{kWh}$ respectively and the total load demand per day is $40.5 \mathrm{kWh}$. The DG sources are controlled individually using an inverter and coupled together in an AC bus with a rating of $400 \mathrm{~V}$ and $50 \mathrm{~Hz}$. The entire SHRES configuration is shown in Figure 1.

\section{AC BUS 400V, $50 \mathrm{~Hz}$}

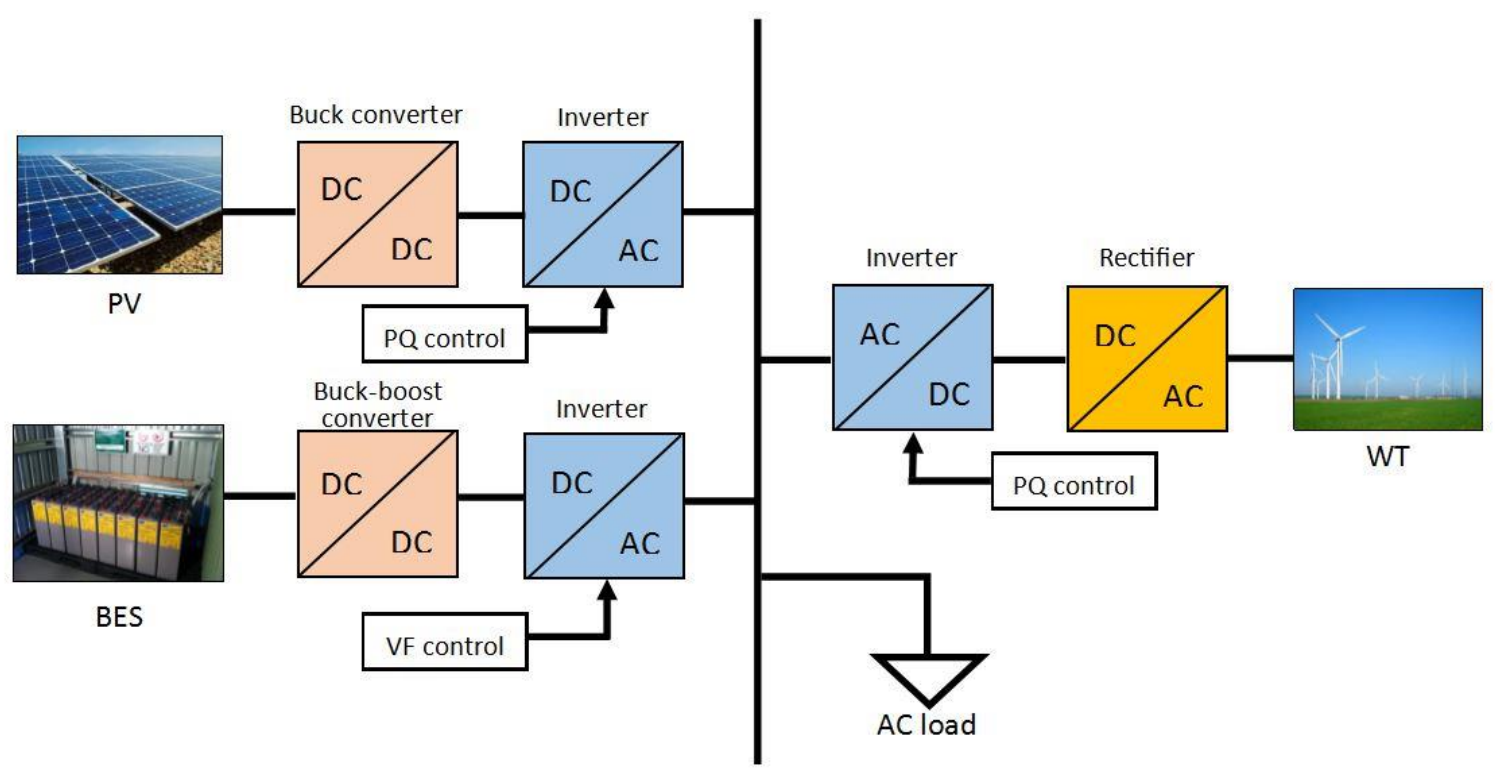

Figure 1. SHRES configuration 


\subsection{Control Strategy of the Shres}

Master-slave control is chosen as the control strategy for this SHRES whereby the master DG sources will operate in voltage and frequency (VF) control while the slave DG sources will operate in active and reactive power (PQ) control. The BES inverter is selected as the master DG source while the PV and WT inverter are selected as the slave DG source for the stand-alone PV, WT and BES hybrid system as shown in Figure 1.

The objective of the VF control is to provide a reference voltage and frequency for the system [9] while the objective of the PQ control is to produce active and reactive power for the SHRES according to the reference given by the central controller [10]. Through elimination of the interaction effect between the direct axis current and the quadrature axis current in the PQ control, the inverter's active power and reactive power can be directly controlled. PI controllers have been used to eliminate the error between the direct and quadrature axis currents reference and measured values [10].

Accurate control of the PV inverter's active power is essential for PV curtailment applications. Initially, the PQ control PI controllers will use the traditional trial and error method to tune its parameters. However, the PI controller parameters obtained using the trial and error method is not optimal and the process of tuning the PI controller using the trial and error method is a very tedious and time consuming process [11]. The fixed gains from the controller tuned by trial and error method are also unable to handle fast changes of operation points of the SHRES. As a result, the PV inverter active power PI controller's parameters have to be optimized to ensure a fast and accurate response. Thus, the PV inverter active power PI controller with the parameters obtained from the trial and error method is to be replaced with the proposed adaptive controllers, which are an adaptive controller and an optimized adaptive controller. The entire PQ control of the PV inverter with the proposed adaptive controllers to replace the active power PI controller is shown in Figure 2. The proposed methodology for the implementation of the adaptive controllers will be discussed in the next section.

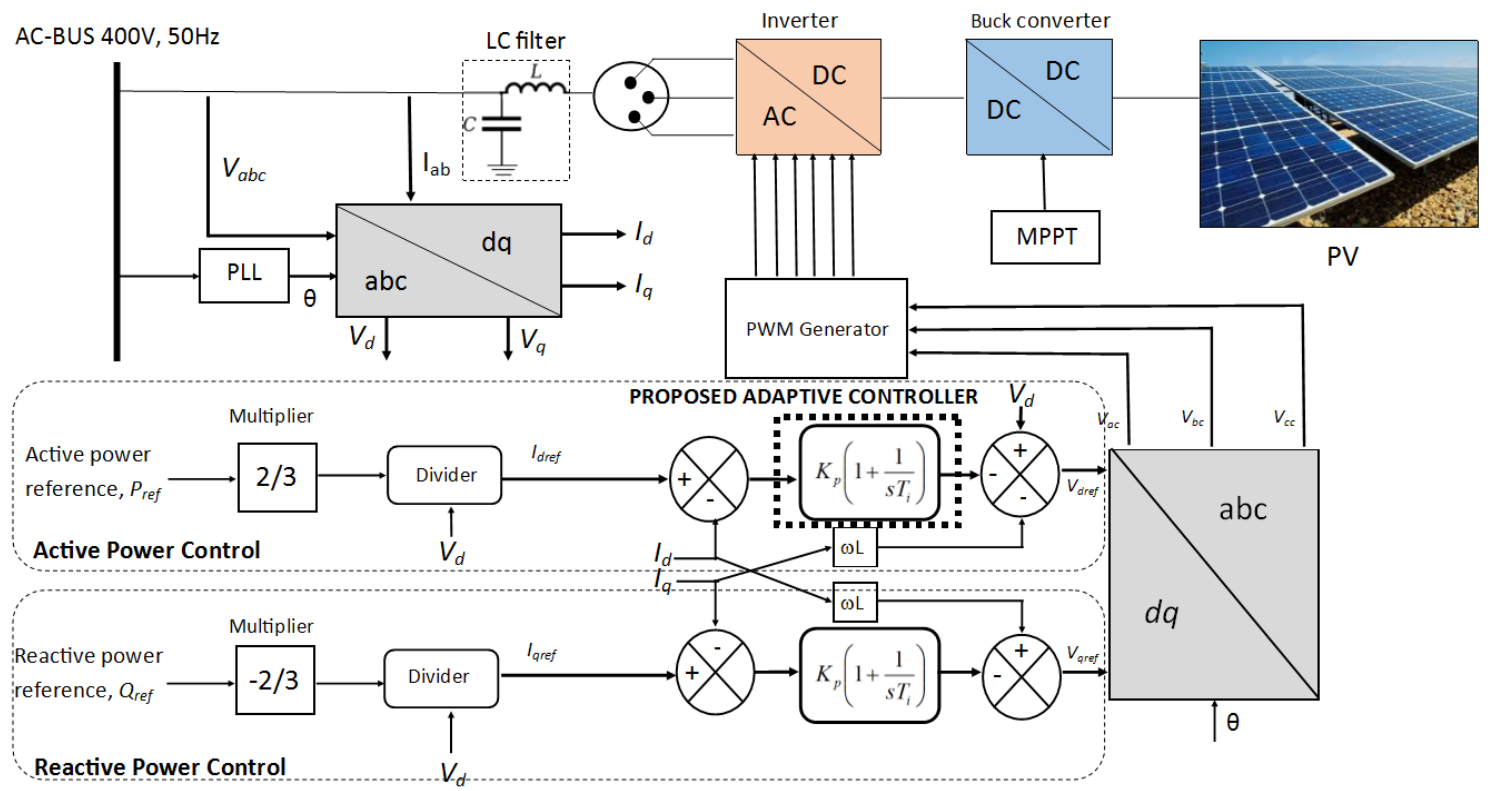

Figure 2. Proposed adaptive controller in the PV inverter

\section{PROPOSED METHODOLOGY FOR THE IMPLEMENTATION OF THE ADAPTIVE CONTROLLERS}

As discussed in the previous section, the adaptive controllers are proposed to replace the active power PI controller of the PV inverter which was tuned using the trial and error method to optimize the PI controller parameters. In this work, an adaptive controller and an optimized adaptive controller is proposed replace the PI controller which was tuned using the trial and error method. The adaptive PI controller is essentially a PI controller with two additional auxiliary PI controllers aiming to optimize the adaptive PI controller parameters dynamically. The optimized adaptive controller applies the GA optimization on the auxiliary PI controller to obtain its optimal parameters. The performance of the controllers are evaluated by 
minimizing the integral of the time weighted absolute error (ITAE) criterion. The objective function of ITAE is shown as:

$$
I T A E=\int_{0}^{\infty}(t .|e(t)|) \cdot d t
$$

where $\mathrm{e}$ is the error of the direct axis current and $\mathrm{t}$ is the time period in hours. The ITAE criterion is an indication of how close the measured PV inverter output power is able to match the varying PV reference. Thus, a lower number of the ITAE signify an improved performance of the SHRES as the error between the measured and reference value is reduced. The proposed adaptive controller is presented in Section 3.1 while the proposed optimized adaptive controller is presented in Section 3.2.

\subsection{Proposed Adaptive Controller}

An adaptive controller is adopted from [8] and proposed to replace the PV inverter's active power PI controller in the SHRES. The proposed adaptive controller is able to optimize the PI controller parameters dynamically, allowing the PI controller to respond to fast changes of operation points. As a result, the proposed adaptive controller is able to overcome the disadvantage of fixed gain PI controller parameters. The adaptive controller structure consists of an adaptive PI controller with two auxiliary PI controllers. The role of the auxiliary PI controllers is to optimize the PI controller parameters during operation of the SHRES. One auxiliary PI controller will control the active power PI controller proportional gain, KpP and another auxiliary PI controller will control the active power controller integral time constant, TiP. The proposed auxiliary PI controllers are designed based on the feedback from the error signal and first derivative of the PV inverter's output power. Thus, in the adaptive controller, the PI parameters are automatically adjusted when there is an imbalance between the power measured from the PV inverter's output and the reference power given. Additionally, a gain controller is added onto the adaptive controller to decrease the amplitude of oscillation caused from the fluctuation of PV output power which will result in increased system stability. The adaptive controller does not require high computational time. However, it does makes the system more complex and more tedious as the two additional auxiliary PI controllers that are added require tuning as well. The structure of the adaptive controller is shown in Figure 3.

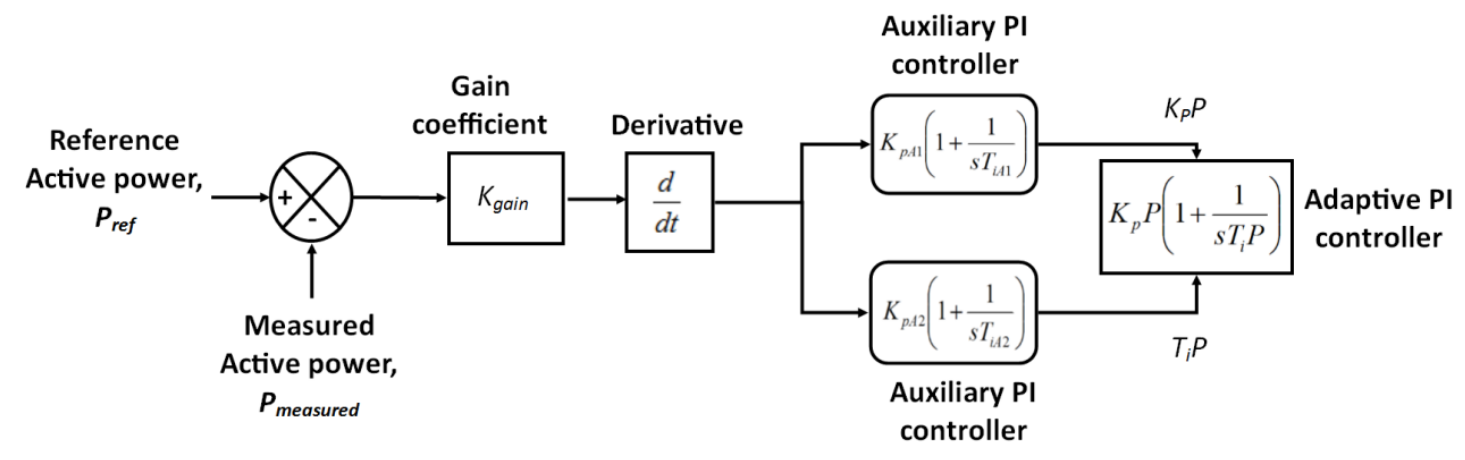

Figure 3. Adaptive controller structure

\subsection{Proposed Optimized Adaptive Controller}

In this section, an optimized adaptive controller is proposed where the two auxiliary PI controllers from the proposed adaptive controller are optimized using GA. The GA is implemented into both the auxiliary PI controllers of the proposed adaptive controller to form an optimized adaptive controller. The proposed optimized adaptive controller aims to determine the optimal parameters for the auxiliary PI controllers while operating a dynamic adaptive PI controller. The optimized adaptive controller is able to reduce the tedious process of tuning the two auxiliary PI controllers but will require higher computational time than the proposed adaptive controller.

The GA is implemented in the two auxiliary PI controllers in Figure 3 to determine its optimal parameters. GA is selected as the optimization method to optimize all four parameters from both of the auxiliary PI controllers. The four parameters are the proportional gain $\left(K_{p A l}\right)$ and integral time constant $\left(T_{i A l}\right)$ of the auxiliary PI controller that controls $K_{p} P$ and the proportional gain $\left(K_{p A 2}\right)$ and integral time constant 
$\left(T_{i A 2}\right)$ of the auxiliary PI controller that controls $T_{i} P$. The optimal value of the auxiliary PI controller parameters obtained from GA after 100 iterations is used for the optimized adaptive controller. The structure of the optimized adaptive controller is shown in Figure 4.

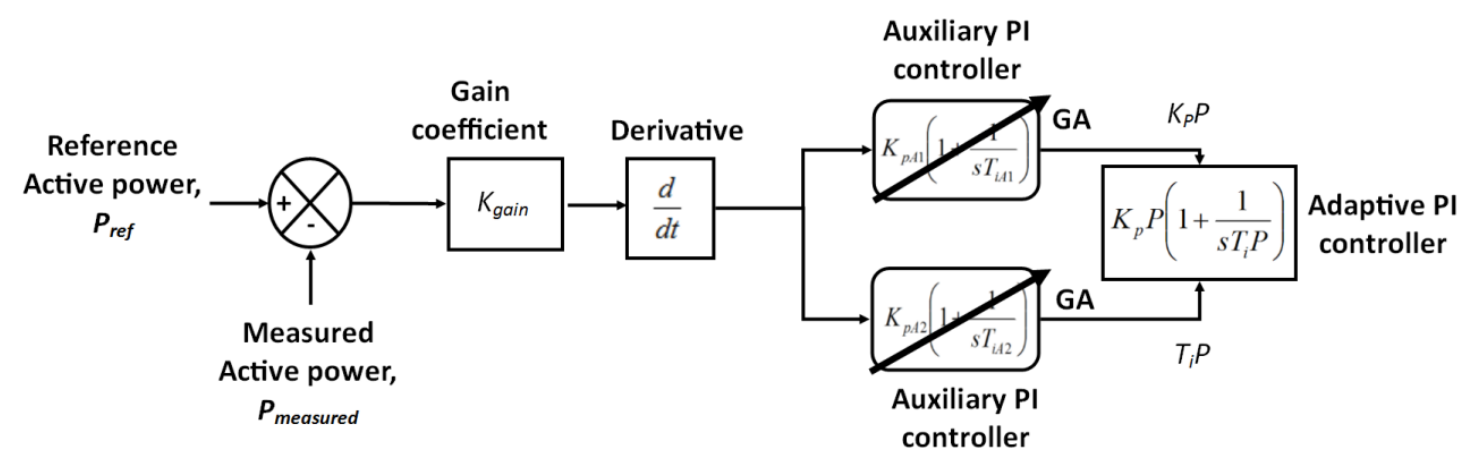

Figure 4. Optimized adaptive controller structure

\section{SIMULATION RESULT AND DISCUSSION}

The stand-alone PV, WT and BES hybrid system is simulated for 24 hours of load with a varying $\mathrm{PV}$ reference. The simulation is conducted in the PSCAD/EMDTC environment and all the operations of the PV, WT, BES and its inverters are considered ideal. As discussed earlier, an adaptive controller and an optimized adaptive controller was proposed to determine the PV inverter active power PI controller parameters. Thus, the varying PV reference is designed to test the performance of the PV inverter active power PI controllers. The reference and measured PV inverter output power were recorded while evaluating its overshoot and steady state error of the PV inverter throughout the entire simulation duration. The performance of the adaptive controllers are evaluated by minimizing the ITAE criterion in eq. (1). The improvement of the error of each adaptive controller are compared against the traditional PI controller and against each other. The comparison of the ITAE criterion obtained from the traditional PI controller and the adaptive PI controllers are shown in Table 1. The PV output power in the SHRES using the traditional PI controller and the adaptive PI controllers are shown in Figure 5.

From table 1, the ITAE criterion obtained from the traditional PI controller which was tuned by the trial and error method is 9.16651. The adaptive controller obtained an improved ITAE criterion of 5.80829 while the optimized adaptive controller obtained the lowest ITAE criterion of 5.26208. Thus, both the adaptive controller and the optimized adaptive controller are able to enhance the performance of the SHRES significantly with an error improvement of $36.63 \%$ and $42.59 \%$ respectively. This was mainly because the $K_{p} P$ and $T_{i} P$ of the adaptive controllers are dynamic as the parameters are able to self-adjust and converge to its optimal value based on the error feedback.

From Figure 5(a), we can observe that the PV output power using the traditional PI controller have recorded large overshoots during the big change of reference PV on the $6^{\text {th }}, 15^{\text {th }}$ and $21^{\text {st }}$ hour. This is because the traditional PI controller uses a fixed gain and is unable to handle fast changes of the operation points. The steady state error of the PV output power using the traditional PI controller is also high, as the PI controller parameters are not optimized. Therefore, it is no surprise that this is reflected on the ITAE of the PV output using the traditional PI controller where it recorded the highest error. From Figure 5(b), the large overshoots that was seen during the big change of reference PV on the $6^{\text {th }}, 15^{\text {th }}$ and $21^{\text {st }}$ hour have been reduced. The steady state error of the PV output power using the adaptive controller is significantly better as well. This is because the adaptive PI controller have two additional auxiliary PI controllers that assist in adjusting the PI controller parameters to its optimal value dynamically.

Lastly, the optimized adaptive controller is proposed to combine the dynamic feature of the adaptive controller with the precise tuning of the GA. Both auxiliary PI controllers of the adaptive controller are optimized using the GA optimization method as discussed in Section 3.2 to overcome the tedious process to tuning the auxiliary PI controllers. In Figure 5(c), the overshoot of the PV output power recorded on the $6^{\text {th }}$ and the $12^{\text {th }}$ hour is slightly higher when using the optimized adaptive PI controller than the adaptive PI controller. On the other hand, the improvement in overshoot was recorded on $9^{\text {th }}, 15^{\text {th }}$ and $21^{\text {st }}$ hour and an overall improvement in steady state error throughout 24 hours was also noticed when optimized adaptive PI controller was used. Although the computational time is higher, it can be seen clearly that the optimized adaptive controller provided the best error improvement compared to the traditional PI controller and the

Adaptive Controllers for Enhancement of Stand-Alone Hybrid System Performance (Yew Weng Kean) 
adaptive PI controller. Thus, the optimized adaptive controller is the promising controller to optimize the PI controller parameters.

Table 1. ITAE of PV Output

\begin{tabular}{ccccc}
\hline & $K_{p}$ & $T_{i}$ & ITAE & $\begin{array}{c}\text { Error } \\
\text { Improvement }\end{array}$ \\
\hline Traditional PI controller & 0.03 & 1.6 & 9.16651 & - \\
Adaptive PI controller & Dynamic & dynamic & 5.80829 & $36.63 \%$ \\
Optimized adaptive PI controller & Dynamic & dynamic & 5.26208 & $42.59 \%$ \\
\hline
\end{tabular}

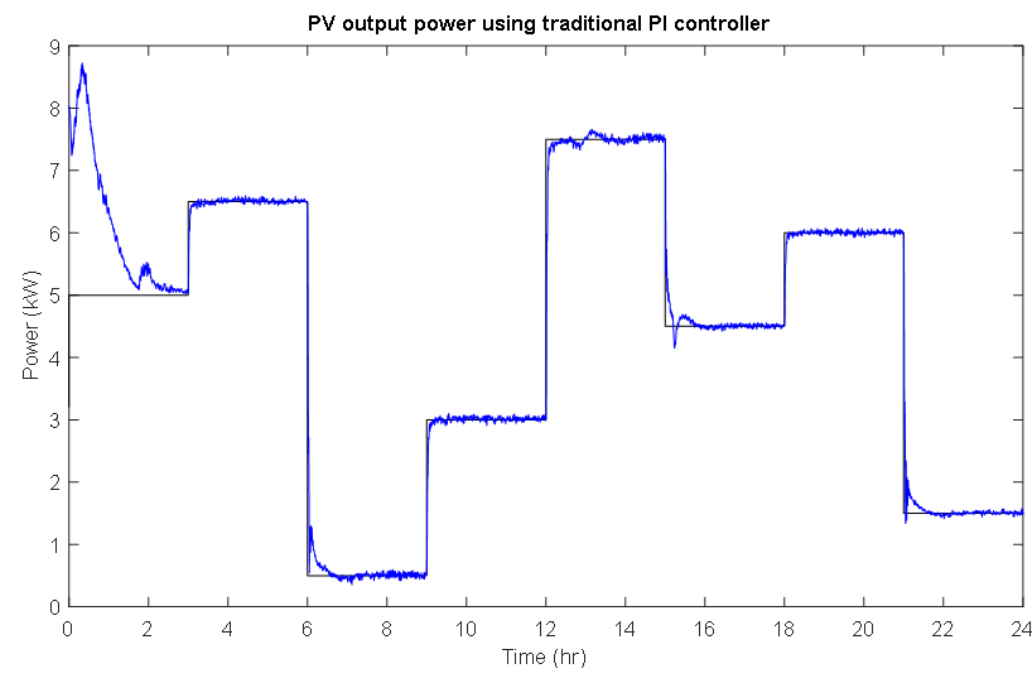

(a)

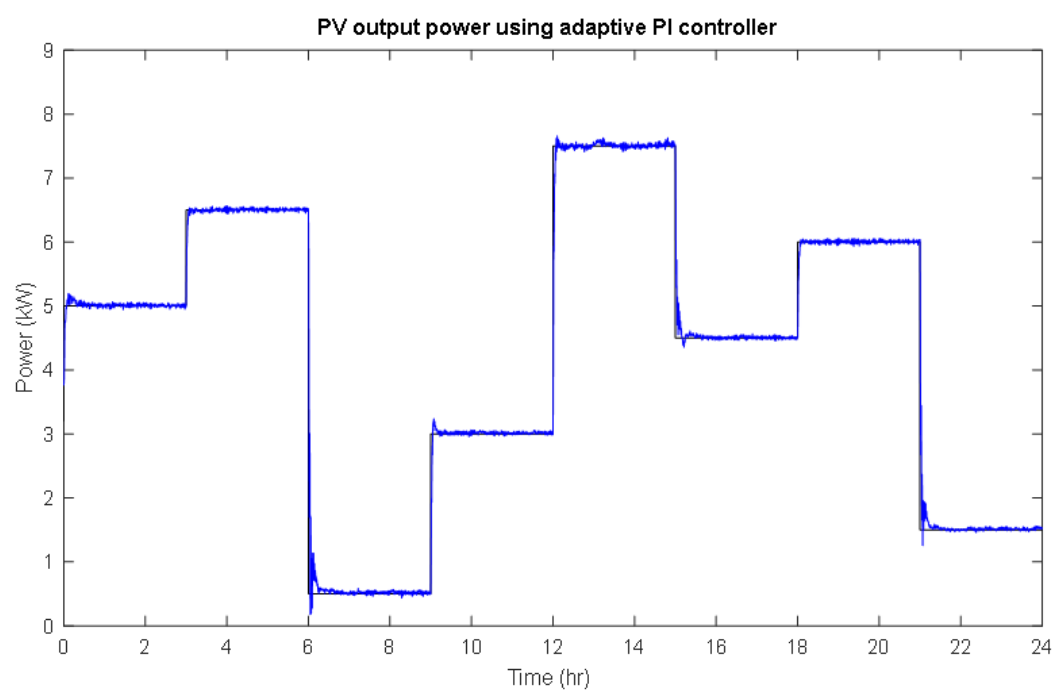

(b) 


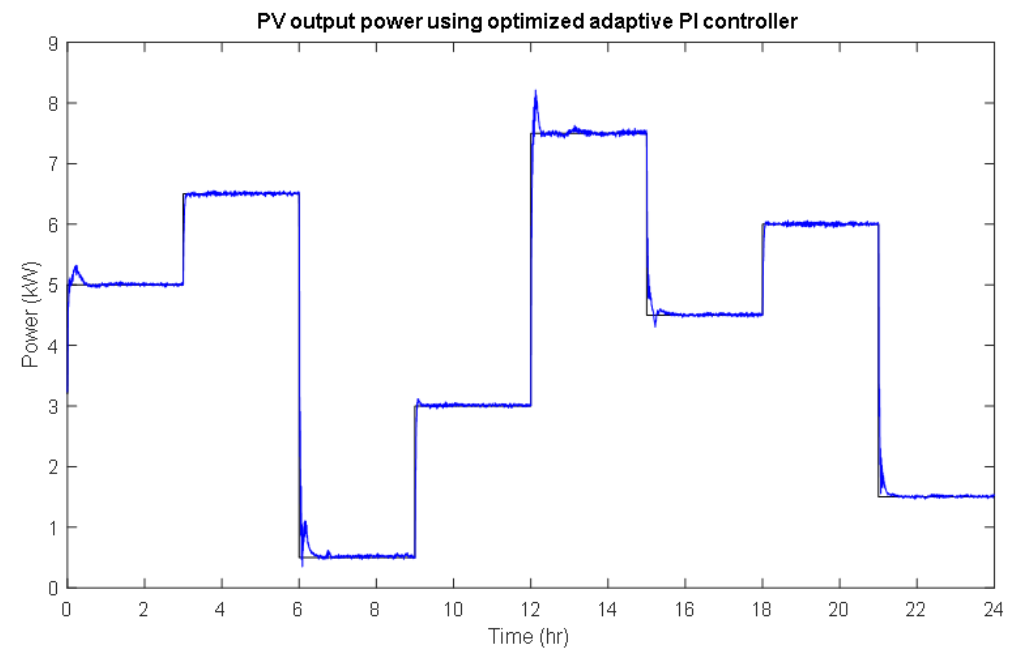

(c)

Figure 5. Output power of PV in SHRES with (a) traditional PI controller (b) adaptive PI controller (c) optimized adaptive PI controller

\section{CONCLUSION}

In conclusion, the performance of the SHRES has been improved through the implementation of the adaptive controllers to optimize the active power PI controller parameters. Therefore, an adaptive controller and an optimized adaptive controller was proposed and designed in this paper. Their results were evaluated by minimizing the objective function which was the ITAE criterion. Simulation results showed that the optimized adaptive controller is the promising controller to optimize the PI controller parameters as it recorded an error improvement of $42.59 \%$. The dynamic optimized adaptive control is more adept at handling the fast changes of the SHRES operation. Other optimization techniques can be considered to optimize the adaptive control for future applications.

\section{ACKNOWLEDGEMENTS}

The authors would like to thank Universiti Tenaga Nasional (Bold grant project code:10289176/B/9/2017/49) for supporting the research work.

\section{REFERENCES}

[1] M. C. Chandorkar, D. M. Divan, and R. Adapa, "Control of parallel connected inverters in standalone ac supply systems,” IEEE Trans. Ind. Appl., vol. 29, no. 1, pp. 136-143, 1993.

[2] M. Z. Daud, A. Mohamed, M. A. Hannan, M. Z. Daud, A. Mohamed, and M. A. Hannan, “An Optimal Control Strategy for DC Bus Voltage Regulation in Photovoltaic System with Battery Energy Storage,” Sci. World J., vol. 2014, pp. 1-16, 2014.

[3] M. S. Mahmoud, N. M. Alyazidi, and M. I. Abouheaf, "Adaptive intelligent techniques for microgrid control systems: A survey,” Int. J. Electr. Power Energy Syst., vol. 90, pp. 292-305, 2017.

[4] E. J. Oliveira, L. M. Honorio, A. H. Anzai, and T. X. Soares, "Linear Programming for Optimum PID Controller Tuning," Appl. Math., vol. 5, no. 6, pp. 886-897, 2014.

[5] W. Bai, M. R. Abedi, and K. Y. Lee, "Distributed generation system control strategies with PV and fuel cell in microgrid operation,” Control Eng. Pract., vol. 53, pp. 184-193, 2015.

[6] D. C. Das, A. K. Roy, and N. Sinha, "Genetic algorithm based pi controller for frequency control of an autonomous hybrid generation system,” Proc. Int. MultiConference Eng. Comput. Sci., vol. 2, 2011.

[7] H. M. Hasanien, "An Adaptive Control Strategy for Low Voltage Ride Through Capability Enhancement of GridConnected Photovoltaic Power Plants,” IEEE Trans. Power Syst., vol. 31, no. 4, pp. 3230-3237, 2015.

[8] A. Pouryekta, V. K. Ramachandaramurthy, N. Mithulananthan, and A. Arulampalam, "Islanding Detection and Enhancement of Microgrid Performance,” IEEE Syst. J., pp. 1-11, 2017.

[9] Y. Wang, Z. Lu, Y. Min, and S. Shi, "Comparison of the voltage and frequency control schemes for voltage source converter in autonomous microgrid," 2nd Int. Symp. Power Electron. Distrib. Gener. Syst., pp. 220-223, 2010.

[10] W. Bai and K. Lee, Distributed Generation System Control Strategies in Microgrid Operation, vol. 47, no. 3. IFAC, 2014. 
[11] S. Pareek, M. Kishnani, and R. Gupta, "Optimal tuning Of PID controller using Meta heuristic algorithms," in 2014 International Conference on Advances in Engineering \& Technology Research (ICAETR - 2014), 2014, vol. 7, no. 2, pp. 1-5.

\section{BIOGRAPHIES OF AUTHORS}

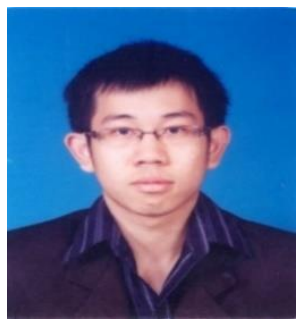

Yew Weng Kean obtained his bachelor degree in Electrical Power Engineering from Universiti Tenaga Nasional in 2013. He is currently pursuing his Ph.D degree from Universiti Tenaga Nasional under the sponsorship of Yayasan Tenaga Nasional. Presently, he is also a Research Assistant in Universiti Tenaga Nasional. His areas of interest are microgrid, smart grid and renewable energy integration. He is also a Graduate member of the Institution of Engineers Malaysia (IEM).

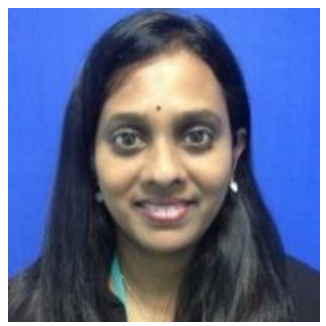

Agileswari K. Ramasamy was born in Taiping, Perak and received her B.Sc (Engineering) degree from Purdue University, USA in 1995 under the sponsorship of Yayasan Tenaga Nasional. She obtained her MSc. (Control System) from Imperial College, London in 2001 and $\mathrm{PhD}$ in Electrical Engineering from Universiti Tenaga Nasional (UNITEN), under the sponsorship of UNITEN. She is currently an Associate Professor in the Department of Electronics Communication Engineering at UNITEN and serving as a Deputy Dean of Research and Postgraduate for College of Engineering, UNITEN. She is also a Chartered Member of the Institution of Engineering and Technology (IET). She is currently active in research and consultancy in control system, power system, power quality, energy efficiency and renewable energy. She has headed several research projects to date and has successfully published several indexed journals.

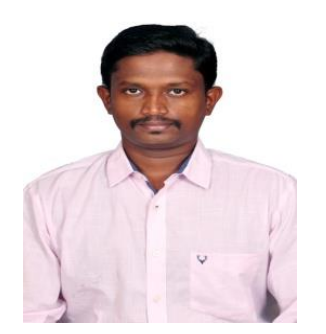

Shivashankar Sukumar obtained his PhD degree from University of Malaya, Malaysia in the year 2017. He is currently working as Post Doctoral Researcher from University Tenega National. His area of research are renewable energy integration, distribution system automation, and application of battery storage for low carbon grids.

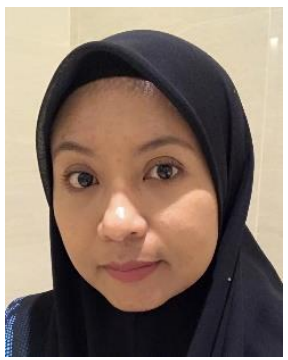

Dr. Marayati is the Director in the Institute of Power Engineering (IPE) and Senior Lecturer in the Department of Electric Power at The National Energy University. She received her Bachelor of Electrical Power and Master in Electrical Engineering in 2002 and 2006 respectively. She was awarded with $\mathrm{PhD}$ in Electrical, Electronics and System Engineering from the National University of Malaysia in 2011. She has been actively involved in research and consultancies work related to energy, demand side respond, power system stability and renewable energy. 